\title{
Perceptions Of The Support Needed By Teacher Counsellors In Secondary Schools In The Ohangwena Region Of Namibia
}

\author{
Emilia N. Mbongo \\ Ministry of Education, Oshikoto Education Region \\ Andrew D. Möwes \\ Charles C. Chata \\ Faculty of Education, University of Namibia
}

\begin{abstract}
This paper explored teacher counsellors' views regarding the support needed in senior secondary schools in Ohangwena region of Namibia. The study was quantitative in nature and a non-experimental design that involved a survey was used. The population of the study comprised of the teacher counsellors in all the senior secondary schools in Ohangwena region. Data was collected using questionnaires which were administered to a sample of twenty-six (26) teacher counsellors. Teacher counsellors were purposively sampled. The data was analysed by use of descriptive statistics in the form of frequencies and percentages. Results indicated that teacher counsellors needed to be supported by parents, teachers, school principals, Inspectors of Education, Regional School Counsellors, and other teacher counsellors, in order to improve the quality of School Guidance and Counselling services in that region of the country. The study recommended that principals, teachers and Inspectors of Education should be educated about the importance of guidance and counselling in schools and their role in the implementation of it. It was also recommended that the number of Regional School Counsellors should be increased to enable them to support the schools in the implementation of guidance and counselling.
\end{abstract}

Keywords: Teacher counsellor; School counselling; Support; Ohangwena Region; Namibia

\section{Introduction}

Guidance and counselling in schools plays a vital role in preventing educational, emotional, social, personal and other problems among secondary school students (Eyo, Joshua, Esuong, 2009). In addition, 
Lunenburg (2010) emphasized that the purpose of guidance and counselling in schools should be to help individual learners to develop the ability to understand themselves, to solve their own problems, and to make appropriate adjustments to their environment. The need for guidance and counselling in schools is further necessitated by the social and economic challenges that today's children and youth face (Bor, Ebner-Landy, Gill \& Brace, 2002). The situation in Namibia is worsened by the HIV/AIDS pandemic, which has left many children orphaned and vulnerable (Education Management Information Systems (EMIS), (2012). Fourie (2010) reported that the Ministry of Education in Namibia identified as a priority area the counselling and support of learners affected and/ infected by HIV/AIDS and other vulnerable children. Efforts were thus made to establish Counselling Support Groups in schools in the country, in order to give the necessary support to learners in need.

The National External Schools Evaluation (NESE) annual reports of 2007 and 2008 showed that guidance and counselling services were not fully functional in most schools in Namibia including the senior secondary schools in Ohangwena Region. The reports indicated that (a) the provision for emotional, physical and social needs of learners was weak or non-existent in $47 \%$ of secondary schools and $78 \%$ of primary schools; and (b) the curricular and vocational guidance of learners was generally poor or non-existent in $58 \%$ of secondary, $71 \%$ of combined and $47 \%$ of primary schools visited in 2008.

Reports for the Ohangwena region revealed that most schools were not attending to the emotional, physical and social needs of the learners; learners were not provided with information and advice in preparation for choice in education, training or employment and the trained teacher counsellors were not providing counselling to learners in need (Ministry of Education, 2008). Clearly, the situation of the School Guidance and Counselling (SGC) in the country, particularly in Ohangwena region is not encouraging. As the NESE reports indicated, guidance and counselling remain very poor in a lot of schools.

In order for the program of Guidance and Counselling to be successful, teacher counsellors need to be supported by all stakeholders in education including school principals, parents, learners and teachers. Principals and other teachers need make efforts to understand and appreciate the value of guidance and counselling services at schools. DeLuccia-Reinstei (2009) argues that the school counsellors' motivation to help student's increases significantly when they do not feel isolated from and not supported by the school staff. DeLuccia-Reinstei (2009) further added that principals, as heads of the schools, have the responsibility for overseeing the implementation of guidance and counselling in their schools. According to 
Maluwa-Banda (1998), principals are in a key position to ensure a successful programme by showing interest in it, having a positive attitude towards it, maintaining open lines of communication with teaching staff, counsellors and students concerning the programme, and promoting a climate conducive to professional development and student growth. In his study, one of his findings was that school counsellors received very little support from the administration. In addition, support from other teacher counsellors (peer support) is also important. This is done through cluster meetings where all teacher counsellors in a cluster come together regularly to share ideas and to jointly engage in problem solving and to mutually support each other (Ministry of Education, 2006).

Furthermore, it is trusted that such meetings would be motivational and help sustain the existence of guidance and counselling services in schools. According to the Ministry of Education (2006) in a document titled "Guidelines for the Cluster Facilitator for Counselling (CFC)" cluster meetings would curb isolation and teacher counsellors would be able to benefit from the experiences of their peers in schools.

DeLuccia-Reinstei (2009) is of the opinion that regular training keep school counsellors educated and well-informed. School counsellors thus need to be supported in terms of continuous training to keep them updated. In a study done by Gora, Swatzky and Hague (1992), counselling staff suggested that they could benefit from colleague support groups or in-service programs that would give them opportunities for renewal and camaraderie. Activities of this nature would provide school counsellors with additional skills as well as share experiences with others and would perhaps alleviate some of the job stress associated with school guidance and counselling. Other things that could be done in an effort to support school counsellors include reducing their workload, providing facilities such as a room for individual guidance and counselling for and continuous support from Reginal School Counsellors (RSC) and regional officials, such as Inspectors of Education and Education Officers.

This paper therefore assessed the views of teacher counsellors in secondary schools in the Ohangwena education region on the support needed in order to improve the provision of guidance and counselling in schools.

\section{METHOD}

\section{Research design}

The study followed a quantitative approach to research. A nonexperimental design that involved a survey was used in the study. A survey research determines and reports the way things are (Gay, Mills \& Airasian, 2009). Since the study sought to obtain information about SGC from the 
teacher counsellors' perspective, the survey method was deemed appropriate to the study.

\section{Sample}

The sample of the study comprised of all senior secondary school teacher counsellor (approximately 30) from ten senior secondary schools in Ohangwena region. The purposive sampling procedure was used in determining the sample. Purposive sampling is a process of selecting a sample that is believed to be representative of the group to be sampled (Gay et. al, 2009). Teacher counsellors were selected to take part in the study as they have the information and insight knowledge with regard to guidance and counselling in secondary schools. Thirty (30) questionnaires were distributed to the teacher counsellors and of these, 26 questionnaires were returned, which represents approximately $87 \%$ of the entire population.

\section{Research Instruments and Procedure}

Data was collected using researcher-designed questionnaires. The questionnaire comprised scaled questions. Teacher counsellors were asked to respond to a three-point rating scale of very important, important and not important. Teacher counsellors were also asked to indicate the degree of support they received from the different categories of people listed. A threepoint rating scale of no support, little support and a lot of support was used. The use of questionnaires ensures that responses are gathered in a standardised way, so questionnaires are more objective. A pilot study was done with five teacher counsellors from five secondary schools in Ohangwena Region. This was done to determine whether participants would understand the questions; to provide information about deficiencies as well as suggestions for improvement; and to find out whether the questions were relevant and appropriate.

After the proposal was approved by the University’s Postgraduate Studies Committee to conduct the study, further permission was sought and granted from the Permanent Secretary of the Ministry of Education and the Director of Education: Ohangwena Directorate.

\section{Data analysis}

The Statistical Package for Social Sciences (SPSS), which is an application that provides statistical analysis of data, was used to analyse the bulk of the teacher counsellors' responses. Descriptive summary statistics in the form of simple frequencies and percentages were used. 


\section{RESULTS AND DISCUSSION}

The section of this presents the demographic data of teacher counsellors, followed by the results and discussion on support needed by teacher counsellors. The results are presented below:

\section{Demographic variables of teacher counsellors}

Table provides the frequency and percentage frequency of the demographic variables of teacher counsellors who responded to the questionnaire.

Table 1: Frequency distribution of demographic variables of teacher counsellors

\begin{tabular}{|c|c|c|c|}
\hline Characteristic & Category & $\mathbf{f}$ & $\%$ \\
\hline \multirow{2}{*}{ Gender } & Male & 6 & 23.1 \\
\hline & Female & 20 & 76.9 \\
\hline \multirow{7}{*}{ Age } & Younger than 25 & 2 & 7.7 \\
\hline & $26-29$ & 6 & 23.1 \\
\hline & $30-34$ & 3 & 11.5 \\
\hline & $35-39$ & 7 & 26.9 \\
\hline & $40-49$ & 5 & 19.2 \\
\hline & $50-59$ & 3 & 11.5 \\
\hline & 60 or more & 0 & 0 \\
\hline \multirow{7}{*}{ Qualifications } & $\begin{array}{ll}\text { Degree } & \text { +additional } \\
\text { postgraduate qualification }\end{array}$ & 6 & 23.1 \\
\hline & Degree+ teaching diploma & 0 & 0 \\
\hline & Teaching degree & 6 & 23.1 \\
\hline & $\begin{array}{lc}\text { Teaching } & \text { diploma+ } \\
\text { postgraduate qualification }\end{array}$ & 8 & 30.8 \\
\hline & Teaching diploma & 6 & 23.1 \\
\hline & Certificate & 0 & 0 \\
\hline & other & 0 & 0 \\
\hline \multirow{6}{*}{ Position } & Principal & 0 & 0 \\
\hline & Vice-principal & 0 & 0 \\
\hline & Head of Department & 5 & 19.2 \\
\hline & Subject head & 4 & 15.4 \\
\hline & Teacher & 17 & 65.4 \\
\hline & Other & 0 & 0 \\
\hline \multirow{6}{*}{ Teaching experience } & Less than 1 year & 1 & 3.9 \\
\hline & $1-5$ years & 7 & 26.9 \\
\hline & $6-10$ years & 7 & 26.9 \\
\hline & $11-15$ years & 6 & 23.1 \\
\hline & $16-20$ years & 2 & 7.7 \\
\hline & More than 20 years & 3 & 11.5 \\
\hline \multirow{5}{*}{ Counselling experience } & Less than 1 year & 7 & 26.9 \\
\hline & $1-2$ years & 4 & 15.4 \\
\hline & 3-4 years & 10 & 38.5 \\
\hline & 5-10 years & 5 & 19.2 \\
\hline & More than 10 years & 0 & 10 \\
\hline
\end{tabular}

\section{Gender:}

The majority of participants (76.9\%) were female teacher counsellors as compared to only (23.1\%) male teacher counsellors. 
Age:

Responses pertaining to age showed that most of the teacher counsellors were in the age category of 35-39 years (26.9\%). This was followed by teacher counsellors in the age categories of $26-29$ years and 40 - 49 years, with $(23,1 \%)$ and $(19.2 \%)$ respectively. Teacher counsellors in the age categories of $30-34$ years and 50 - 59 years were equally represented with $(11.5 \%)$ each.

\section{Qualifications:}

When the qualifications of teacher counsellors were analysed, it emerged that the majority of teacher counsellors (30.8\%) had a teaching diploma plus a postgraduate qualification. This was followed by teacher counsellors who are having a teaching degree and those with a teaching diploma and degree + additional postgraduate qualification at (23.1\%) each. None of the participants had a degree + teaching diploma or a certificate.

\section{Position:}

The majority of the teacher counsellors who participated in the study were just ordinary teachers (65.4\%), with (19.2\%) and (15.4\%) being Heads of Departments and subject heads respectively. None of the participants were principals or vice-principals.

\section{Teaching experience:}

The majority (26.9\%) of the teacher counsellors had 1-5 years and 610 years of teaching experience. Those with 11-15 years, more than 20 years and 16-20 years of teaching experience had (23.1\%), (11.5\%), and (7.7\%) respectively. Respondents with less than one year of teaching experience had the lowest representation of only (3.9\%).

\section{Counselling experience:}

The majority of the teacher counsellors (38.5\%) fell in the 3-4 years range of experience as teacher counsellors. The table further shows that a considerable number of them had experience as teacher counsellors of less than a year (26.9\%). This was followed by respondents with experience as teacher counsellors of 5-10 years at (19.2\%) and (15.4\%) respectively. None of the respondents had counselling experience of more than ten years.

\section{Type of support}

The following items concern the types of support needed by teacher counsellors in order for them to carry out their duties effectively. Teacher counsellors were asked to rate the suggested types of support according to 
what they believed to be more important and those which were not very important. The results are summarised in Table 2.

Table 2: Type of support teacher counsellors need

\begin{tabular}{|c|c|c|c|c|c|c|c|c|}
\hline \multirow[t]{3}{*}{ Item } & \multicolumn{8}{|c|}{$\begin{array}{l}\text { EXTENT OF AGREEMENT OR } \\
\text { WITH STATEMENT }\end{array}$} \\
\hline & \multicolumn{2}{|c|}{$\begin{array}{l}\text { Very } \\
\text { important }\end{array}$} & \multicolumn{2}{|c|}{ Important } & \multicolumn{2}{|c|}{$\begin{array}{l}\text { Not } \\
\text { important }\end{array}$} & \multicolumn{2}{|c|}{ Total } \\
\hline & f & $\%$ & f & $\%$ & $f$ & $\%$ & $\mathbf{F}$ & $\%$ \\
\hline $\begin{array}{l}\text { 1. Peer support (support from other } \\
\text { teacher counsellors) }\end{array}$ & 19 & 73.1 & 7 & 26.9 & 0 & 0 & 26 & 100 \\
\hline $\begin{array}{ll}2 . & \text { Support from parents }\end{array}$ & 23 & 88.5 & 3 & 11.5 & 0 & 0 & 26 & 100 \\
\hline $\begin{array}{l}\text { 3. Support from other teachers in } \\
\text { the school }\end{array}$ & 16 & 61.5 & 10 & 38.5 & 0 & 0 & 26 & 100 \\
\hline 4. $\quad$ Support from the principal & 22 & 84.6 & 3 & 11.5 & 1 & 3.85 & 26 & 100 \\
\hline $\begin{array}{ll}\text { 5. } & \text { Support from the Inspector of } \\
\text { Education }\end{array}$ & 18 & 69.2 & 7 & 26.9 & 1 & 3.85 & 26 & 100 \\
\hline 6. $\quad$ Regular visits by RSCs & 17 & 65.5 & 8 & 30.8 & 1 & 3.85 & 26 & 100 \\
\hline $\begin{array}{ll}\text { 7. } & \text { Regular visits by the cluster } \\
\text { facilitator for counselling }\end{array}$ & 12 & 46.1 & 10 & 38.5 & 4 & 15.4 & 26 & 100 \\
\hline 8. $\quad$ Administrative Support & 13 & 50 & 11 & 42.3 & 2 & 7.7 & 26 & 100 \\
\hline $\begin{array}{lll}\text { 9. } & \begin{array}{l}\text { Regular in-service training } \\
\text { (workshops) }\end{array}\end{array}$ & 22 & 84.6 & 4 & 15.4 & 0 & 0 & 26 & 100 \\
\hline
\end{tabular}

The majority of the teacher counsellors (73.1\%) rated support from other teacher counsellors (peer support) as very important. The results indicate that the vast majority of teacher counsellors indicated that there is a need to strengthen peer support among teacher counsellors. This finding is supported by the literature, as the MoE (2006) stated that Cluster Facilitators for Counselling (CFC) groups should be established and should convene regular meetings with teacher counsellors in their clusters to share ideas, to jointly engage in problem solving and to mutually support each other.

The deduction that could be made here is that teacher counsellors would benefit from regular meetings with other teacher counsellors for developmental purposes in order to improve their counselling skills. This will help teacher counsellors to stay motivated, to curb isolation and to be able to benefit from the experiences of other teacher counsellors. With peer support, teacher counsellors give informal support to individual teacher counsellors requesting help with specific problems. Peer support among teacher counsellors should thus be strengthened.

Of the sample, (88.5\%) indicated that support from parents was very important. Only (11.5\%) of the teacher counsellors indicated that support from parents was just important. None of the teacher counsellors said it was not important. The teacher counsellors indicated the need for parents to work together with schools, stating that parents should inform schools about their 
children's medical, social or psychological problems that their children may have. In agreement with this finding are Gora et al. (1992) who reported that lack of parental involvement had been instrumental in a negative outcome, citing that school counsellors had little impact when parents or significant adults in the learner's life refused to acknowledge the problem or when parents neglected to follow through with the suggestions provided. Having parents support schools where guidance and counselling is concerned would help teachers to have a better understanding of learners' behaviour and to be in a better position to assist them. It is thus vital that parents be available to be contacted whenever learners experience difficulties that require the involvement of teacher counsellors so that parents can support the school and the learners accordingly. Parents' support is vital as in most cases, parents know their children better.

The results of the study further showed that more teacher counsellors valued the support of other teachers as very important as indicated by $61.5 \%$. This means that they see other teachers as instrumental in the implementation of guidance and counselling and should thus give the necessary support to teacher counsellors. This finding is supported by DeLuccia-Reinstei (2009) who noted that teacher counsellors' motivation to help learners increases significantly when teacher counsellors do not feel isolated and do not lack support from staff members. This view is also shared by Lunenburg (2010), who stated that at schools where guidance and counselling programmes are effective, staff members work cooperatively. Being cooperative is exhibited in the degree of active interest, mutual help, and collaboration among teachers, the principals and the teacher counsellors. This is important as teachers are the ones who interact with learners on a daily basis and are thus in a better position to notice any behaviour change in a learner. The teacher would then be able to refer such learners to the teacher counsellor.

The lesson that could be learned here is that the teacher counsellors and teachers should work together in identifying and helping learners with difficulties.

Almost all the teacher counsellors believed that in order for school guidance and counselling to succeed, principals should fully support the programme.

This finding is consistent with the views expressed by Myrick (2003), who reported that the principal provides support and encouragement to the teacher counsellors. It is important for the principal, as head of the school, to take the lead in the implementation of the SGC programme at the school. When the principal shows support for the programme, people in the school are likely to follow what he is doing. Furthermore, the responsibilities of teacher counsellors include assisting school managements in dealing with 
severe cases of misconduct by learners. For this to happen, principals and school counsellors need to work together, so that they will be able to assist learners.

The study further revealed that the majority of teacher counsellors rated support from Inspectors of Education as very important. However, as can be seen in Table 2, teacher counsellors generally felt that Inspectors of Education showed very little interest towards guidance and counselling. It is possible that Inspectors of Education themselves do not have much knowledge of school guidance and counselling, making it difficult for them to support teacher counsellors. The challenge would thus be to educate Inspectors of Education about guidance and counselling and the need for it in schools. Only then will they take the lead and support teacher counsellors in the implementation of guidance and counselling in school.

Support from Regional School Counsellors through regular visits to schools was rated as very important by the $65.5 \%$ of the teacher counsellors. According to the Ministry of Education (1994), the duties of RSCs include rendering guidance and counselling to learners and assessing learners who show symptoms of behavioural change and loss of abilities to cope in the educational setting and assisting learners with vocational guidance. For RSCs to be able to render these services to learners, they need to visit schools regularly. Through school visits, RSCs are able to give teacher counsellors guidance in dealing with difficult cases. Monitoring of the guidance and counselling services at schools by RSCs is also done during visits to schools.

The respondents believe that regular visits by Cluster Facilitators for Counselling are important as most of them rated it as important. The Ministry of Education (2006) is in agreement with this, as all clusters were mandated to have a cluster facilitator. Through visits to schools, the cluster facilitators will help teacher counsellors with difficult cases and ensure that the SGC programme is running properly at the schools. However, it would be difficult for CFCs to visit schools as they do not have resources, such as transport to go to schools. In addition, CFCs already have their own loads at their schools. The challenge would thus be to strengthen the support from the cluster facilitators to teacher counsellors by allocating the necessary resources to CFCs and reducing their workload.

Administrative support was seen as very important in the implementation of guidance and counselling in schools, with half (50\%) of the teacher counsellors indicating that it is important. This means that teacher counsellors need to be given administrative support (e.g. paperwork, completing, updating and monitoring cumulative record cards at the school, etc.) in order to effectively render guidance and counselling services to learners. 
Having other school personnel such as teachers and school secretaries assist with the administrative work would ease teacher counsellors' workloads. It is thus imperative that teacher counsellors are given administrative support in order to successfully implement school guidance and counselling in schools.

Furthermore, the majority of teacher counsellors (84.6\%) rated support through regular in-service training as important. This finding is in agreement with that found by Gora et al. (1992) who also found that counselling staff benefited from in-service programmes, and that it gave them renewal and camaraderie. Maluwa-Banda (1998) also identified training of teacher counsellors as important in the implementation of guidance and counselling in schools. In-service training, which brings about improved skills and knowledge, is very important to the success of the guidance and counselling programme in schools. Regular in-service training for teacher counsellors should thus be made a priority, to ensure the success of guidance and counselling programmes in schools.

\section{Degree of support received by teacher counsellors}

Teacher counsellors were asked to indicate the level of support they received from the categories of people listed. More teacher counsellors indicated that they received no support at all from Inspectors of Education and cluster facilitators for counselling, parents and Learners' Representative Councils (items 2, 6, 7 and 9). On the other hand, a significant number of teacher counsellors indicated that they got little support from RSCs, school principals, Head of Departments and other teachers (items 1, 3, 4 and 5). In addition, more teacher counsellors indicated that they got a lot of support from hostel supervisors (item 8 ). The results are summarised in table 3.

Table 3: Degree of support teacher counsellors receive

\begin{tabular}{|c|c|c|c|c|c|c|c|c|}
\hline \multirow[t]{3}{*}{ Category of people } & \multicolumn{8}{|c|}{$\begin{array}{l}\text { AGREEMENT } \\
\text { STATEMENT }\end{array}$} \\
\hline & \multicolumn{2}{|c|}{ No support } & \multicolumn{2}{|c|}{$\begin{array}{l}\text { Little } \\
\text { support }\end{array}$} & \multicolumn{2}{|c|}{$\begin{array}{l}\text { A lot of } \\
\text { support }\end{array}$} & \multicolumn{2}{|c|}{ Total } \\
\hline & f & $\%$ & f & $\%$ & f & $\%$ & f & $\%$ \\
\hline $\begin{array}{ll}\text { 1. The Regional school counsellor } \\
\text { (RSC) }\end{array}$ & 4 & 15.3 & 17 & 65.4 & 5 & 19.2 & 26 & 100 \\
\hline 2. $\quad$ The Inspector of Education & 17 & 65.4 & 9 & 34.6 & 0 & 0 & 26 & 100 \\
\hline 3. $\quad$ The school principal & 4 & 15.3 & 12 & 46.1 & 10 & 38.5 & 26 & 100 \\
\hline 4. The head/s of department $/ \mathrm{s}$ & 3 & 11.5 & 16 & 61.5 & 7 & 26.9 & 26 & 100 \\
\hline 5. $\quad$ Other teachers & 3 & 11.5 & 16 & 61.5 & 6 & 23.1 & 25 & 96.2 \\
\hline $\begin{array}{lll}\text { 6. } & \text { Cluster } & \text { Facilitator } \\
& \text { Counselling (CFC) }\end{array}$ & 21 & 80.8 & 5 & 19.2 & 0 & 0 & 26 & 100 \\
\hline 7. $\quad$ Parents & 12 & 46.1 & 10 & 38.5 & 4 & 15.3 & 26 & 100 \\
\hline 8. The hostel supervisors & 1 & 3.85 & 8 & 30.8 & 10 & 38.5 & 19 & 73.1 \\
\hline $\begin{array}{lll}9 . & \text { Learners' } \\
\text { Council (LRCs) } & \text { Representative }\end{array}$ & 13 & 46.1 & 7 & 26.9 & 4 & 15.3 & 23 & 88.5 \\
\hline
\end{tabular}


The majority of the teacher counsellors (65.4\%) indicated that they received very little support from RSCs. Of the total number of participants, (19.2\%) showed that they got a lot of support from RSCs. Only (15.3\%) indicated that they did not receive any support from them. The majority of the teacher counsellors indicated that they received very little support from the RSCs. As discussed earlier, teacher counsellors indicated that support from the RSCs was very important. The lack of support from the RSCs could be attributed to the fact that Ohangwena Region with nearly 250 schools has only three RSCs (EMIS, 2010). This makes it very difficult for them to reach all the schools and give teacher counsellors the necessary support. This means that supervision, guidance to teacher counsellors and monitoring of guidance and counselling activities by the RSCs at schools are not done on a regular basis. RSCs are instrumental in the implementation of guidance and counselling in schools, thus their supports to teacher counsellors need to be intensified. It should thus follow that more RSC need to be appointed, in order for them to support teacher counsellors accordingly.

An overwhelming majority of the teacher counsellors, (65.4\%) indicated that they received no support at all from Inspectors of Education when it came to guidance and counselling issues, with the remaining (34.6\%) of teacher counsellors saying that they received little support from them. This is in agreement with findings of a study done in Namibia by Vergnani, Frank, Haihambo Ya-Otto and Mushaandja (2010) who established that Inspectors of Education did not play any meaningful role in monitoring school counselling activities and are inadequately informed about counselling and the role they should play in this regard.

Table 2 further shows that $46.1 \%$ of the participants indicated that they received little support from the principals. Only, 38.5\% of the teacher counsellors indicated that they received a lot of support from school principals, with $15.3 \%$ of them saying that they received no support from RSCs. This finding is consistent with results found by Bulus (2001); Denga (2001); and Edet (2008) cited in Eyo et al. (2009), who reported that principals constitute the greatest obstacle to the success of guidance and counselling services in schools. The principal's role is to provide leadership for the guidance and counselling programme. With such an important role to play, lack of support from the principal will definitely hamper the successful implementation of guidance and counselling services in schools.

Principals should therefore render the necessary support to the teacher counsellors and play their part in the implementation of guidance and counselling programmes at their schools.

With regard to the support given to teacher counsellors by Heads of Departments (HoDs), the majority (61.5\%) responded that they received little support, while (26.9\%) indicated that they got a lot of support from 
them. A few teacher counsellors (11.5\%) indicated that they got no support from Heads of Departments. HoDs are second in command at most schools, and as such have a lot of influence at the schools. Whether they support or do not support a programme, they are likely to influence other teachers' attitudes towards such a programme. The reason why HoDs do not support teacher counsellors could be a lack of knowledge about the importance of guidance and counselling in schools. In addition, HoDs might not be aware of the roles they have to play in the implementation of guidance and counselling in schools. A major challenge would thus be to educate HoDs on guidance and counselling and more importantly, on the roles they have to play in the implementation of guidance and counselling.

Furthermore, the majority of the teacher counsellors (61.5\%) indicated that they receive no or little support from fellow teachers. This result is supported by DeLuccia-Reinstei (2009) who contended that teacher counsellors' motivation to help learners increases significantly when they do not feel isolated and do not lack support from staff. Teachers must therefore be made aware of the important role they play in the implementation of SGC.

Teachers are the ones who deal with learners on a daily basis and are thus in a position to identify and refer learners to teacher counsellors for counselling.

With regard to the support given to teacher counsellors by Cluster Facilitators for Counselling (CFCs), an overwhelming majority of the participants (80.8\%) indicated that they received no support from CFCs. The remaining (19.2\%) said they received little support. This is contrary to what was stated by the MoE (2006), that there should be cluster facilitators to render support to other teacher counsellors. This might be due to too much work on the part of cluster facilitators. They are normal teachers with normal teaching loads and they carry the responsibility of guidance and counselling at their schools, in addition to being cluster facilitators. As such, going to schools in their clusters to render support to other teacher counsellors might be difficult. Another reason for the failure of the cluster facilitators supporting other teacher counsellors could be the issue of transport. This is especially true in rural schools, where distances between schools are very long.

More participants (46.1\%) indicated that they received no support from parents, while (38.5\%) indicated that they received little support from them. The remaining $(15.3 \%)$ indicated that they got a lot of support from parents. Paralleling this finding, Gora et al. (1992) found that a lack of parental involvement was instrumental in a negative outcome, citing that school counsellors had little impact when parents or significant adults in the learner's life refused to acknowledge the problem or when parents neglected to follow through with the suggestions provided. The situation in Namibia is 
further worsened by the HIV and AIDS pandemic, which has left many children orphaned. The Ministry of Health and Social Services (MoHSS), (2006 - 2007), revealed that the proportion of children considered to be orphaned at the time of the survey was (28\%) of all children in Namibia. In most cases, these children live with grandparents, who are already burdened with a lot of responsibilities, making their involvement in the education of the children difficult. Parents or guardians should thus be sensitised about the importance of guidance and counselling and what role they need to play. This can be done during parents' meetings.

Hostel supervisors rendered a lot of support as indicated by $38.5 \%$ of the participants. However, $30.8 \%$ of the participants indicated that they received little support from hostel supervisors. In schools, hostel supervisors get to know the learners very well and are thus a great source of information about learners. Some of the duties of hostel supervisors include establishing effective procedures for the care and well-being of learners at the hostel, as well as administrative and disciplinary functions. Efforts should thus be made to include hostel supervisors in the committee for counselling at schools, even if it is just on a "when a need arises" basis.

The results further showed that the majority of the teacher counsellors received no support at all from Learners' Representative Council (LRC). An LRC is a group of learners in a school elected by their fellow learners. For them to support teacher counsellors they need to know and understand what guidance and counselling is all about.

They might not be very knowledgeable in guidance and counselling, thus their support will be minimal. Research has however proven that peer counselling is effective and efforts should therefore be made to involve the LRCs in the guidance and counselling programmes at schools. Learners can be trained to offer guidance and counselling to their peers. This is based on the understanding that learners tend to relate more to those peers with whom they are comfortable. The peer counsellor also assists in identifying and making referrals to the teacher counsellor. Days should be set aside for them to share experiences and information with their peers, through various means such as dramas, role-playing, talks, poetry, etc. In this way, the LRC would thus be providing support to teacher counsellors.

\section{Conclusion and Recommendations}

From the findings of this study, it can be concluded that teacher counsellors viewed the support from different stakeholders as inadequate and that for the guidance and counselling programme to succeed, teacher counsellors should be accorded the necessary support. Inspectors of Education, principals, HoDs and teachers should all be sensitised in school 
guidance and counselling so that they can understand and appreciate the value of the guidance and counselling services in schools.

Principals and HoDs would then be able to see to it that guidance and counselling programmes are implemented and for them to be able to monitor and render support to teacher counsellors. Similarly, teachers will work together with teacher counsellors in identifying and referring learners with difficulties to teacher counsellors.

From the study it also emerged that cluster meetings for counselling do not take place as frequently as they should. Consequently, peer support is lacking among teacher counsellors. It is thus recommended that networking amongst teacher counsellors be strengthened to allow teacher counsellors to share ideas, to jointly engage in problem solving, and to mutually support each other. The study established that teacher counsellors would need support from teachers and principals. It is thus recommended that principals and teachers strengthen their support to teacher counsellors.

The role of parents in the success of the guidance and counselling programmes in schools is indeed a formidable one, which should not be ignored. The study revealed that parental involvement in the guidance and counselling of their children is low. The study therefore recommends that parents play a more active role in this regard. Finally, the study established that the current number of RSCs in the region makes it difficult for them to reach out and fully support teacher counsellors because of the size of the region. It is thus recommended that the Ohangwena Region should appoint more RSCs, preferably, one RSC in each circuit.

\section{References:}

Bor, R., Ebner-Landy, J., Gill, S. \& Brace, C. (2002). Counselling in schools. London: SAGE Publications.

DeLuccia-Reinstei, R. (2009). What are the main causes of burnout stress for school counsellors? Available from: http://www.ehow.com/facts_5565034_main-burnout-stress-schoolcounselors.html\#ixzz0qoawwsdN

Education Management Information Systems (EMIS)(2010). Education statistics in Namibia. Windhoek: Ministry of Education.

Education Management Information Systems (EMIS) (2012). Education statistics in Namibia. Windhoek: Ministry of Education.

Eyo, M. B., Johua, A. M. \& Esuong, A. E. (2009). Attitude of secondary school students towards guidance and counselling services in Cross River State. Edo Journal of Counselling, 3(1), 87-99.

Fourie, S (2010). Background notes to the conference: Counselling and psychosocial support for learners at schools in Namibia. Windhoek. 
Gay, L. R., Mills, G. E. \& Airasian, P. (2009). Educational Research: Competencies for analysis and applications. New Jersey: Pearson Education Inc.

Gora, R., Swatzky D. \& Hague W. (1992). School Counsellors Perceptions of their Effectiveness. In Canadian Journal of Counselling, 26(1), 5-14.

Lunenburg, F. C. (2010). School guidance and counselling services. Schooling, 1(1), 1-9.

Maluwa-Banda, D.W. (1998). School counsellors' perceptions of a guidance and counselling programme in Malawi's secondary schools. In British Journal of Guidance and Counselling, 26(2), 287-295.

Ministry of Education, Namibia. (2008). National External Schools Evaluation (NESE) Annual Report. Windhoek: Ministry of Education.

Ministry of Education, Namibia. (2007). National External Schools Evaluation (NESE) Annual Report. Windhoek: Ministry of Education.

Ministry of Education, Namibia. (2006). Counselling Manual for Teachers: Counselling Guidelines for Specific Difficulties. Windhoek: Ministry of Education.

Ministry of Health and Social Services (MoHSS) [Namibia] and Macro International Inc. (2008). Namibia Demographic and Health Survey 2006 2007. Windhoek: Namibia and Calverton, Maryland: USA.

Myrick, R. D. (2003). Developmental Guidance and Counselling: A Practical Approach. Minneapolis: Educational Media Corporation.

Vergnani, T., Frank, E., Haihambo Ya-Otto, C.K. \& Mushaandja, J. (2010). Evaluation of Counselling Services in Schools in Namibia (unpublished). Windhoek. 